\title{
Temporal comparison and predictors of fish species abundance and richness on undisturbed coral reef patches
}

Elena L.E.S. Wagner, Dominique G Roche, Sandra A Binning, Sharon Wismer, Redouan Bshary

Large disturbances can cause rapid degradation of coral reef communities, but what baseline changes in species assemblages occur on undisturbed reefs through time? We surveyed live coral cover, reef fish abundance and fish species richness in 1997 and again in 2007 on 47 fringing patch reefs of varying size and depth at Mersa Bareika, Ras Mohammed National Park, Egypt. No major human or natural disturbance event occurred between these two survey periods in this remote protected area. In the absence of large disturbances, we found that live coral cover, reef fish abundance and fish species richness did not differ in 1997 compared to 2007. Fish abundance and species richness on patches was largely related to the presence of shelters (caves and/or holes), live coral cover and patch size (volume). The presence of the ectoparasite-eating cleaner wrasse, Labroides dimidiatus, was also related to fish species richness. Our results underscore the importance of physical reef characteristics, such as patch size and shelter availability, in addition to biotic characteristics, such as live coral cover and cleaner wrasse abundance, in supporting reef fish species richness and abundance through time in a relatively undisturbed and understudied region. 


\section{Temporal comparison and predictors of fish species abundance and richness}

\section{2 on undisturbed coral reef patches}

4 Elena L. E. Wagner ${ }^{\dagger}$, Dominique G. Roche ${ }^{\dagger}$, Sandra A. Binning ${ }^{\dagger *}$, Sharon Wismer \& Redouan 5 Bshary

6 Université de Neuchâtel, Institut de Biologie, Émile-Argand 11, 2000 Neuchâtel, Switzerland

$7 \dagger$ Joint first authors

$8 *$ Corresponding author

9 Sandra A. Binning

10 E: binningsandra@gmail.com

11 T: +41327183120

\section{Abstract}

baseline changes in species assemblages occur on undisturbed reefs through time? We surveyed live coral cover, reef fish abundance and fish species richness in 1997 and again in 2007 on 47

17 fringing patch reefs of varying size and depth at Mersa Bareika, Ras Mohammed National Park,

18 Egypt. No major human or natural disturbance event occurred between these two survey periods

19 in this remote protected area. In the absence of large disturbances, we found that live coral cover,

20 reef fish abundance and fish species richness did not differ in 1997 compared to 2007. Fish

21 abundance and species richness on patches was largely related to the presence of shelters (caves

22 and/or holes), live coral cover and patch size (volume). The presence of the ectoparasite-eating cleaner wrasse, Labroides dimidiatus, was also related to fish species richness. Our results 
24 underscore the importance of physical reef characteristics, such as patch size and shelter

25 availability, in addition to biotic characteristics, such as live coral cover and cleaner wrasse

26 abundance, in supporting reef fish species richness and abundance through time in a relatively

27 undisturbed and understudied region.

\section{Introduction}

Coral reefs and the biodiversity they support are declining globally as a result of natural and anthropogenic stressors (e.g. Bellwood et al., 2004; Gardner et al., 2005; De'ath et al., 2012).

Phenomena such as climatic fluctuations, disease outbreaks, species invasions and severe storms can negatively impact coral reef species' abundance and diversity, and are being exacerbated by human activities such as overfishing, pollution and tourism intensity (Hughes 1994; Hughes and Connell 1999; Pandolfi et al. 2003; Gardner et al. 2005; Hasler and Ott 2008; Hoegh-Guldberg and Bruno 2010; De'ath et al. 2012). To better predict the long-term impacts of such disturbances on reef communities, it is critical to understand how these communities change through time in the absence of large perturbations, especially in relatively pristine areas which have not been heavily impacted by tourism or human development (Knowlton and Jackson 2008; Edmunds et al. 2014; Graham et al. 2014; Beldade et al. 2015). This information provides a valuable baseline against which changes caused by disturbances can be assessed. promoting reef resilience, stability and recovery, as well as identifying and managing threats (Hughes et al. 2010; De'ath et al. 2012; Edmunds et al. 2014; Alvarez-Filip et al. 2015). Some successful long-term monitoring programs exist in well-studied regions such as the Hawaiian archipelago, the Great Barrier Reef and the Caribbean (i.e. Hughes and Connell 1999; Gardner et 
47 al. 2005, De'ath et al. 2012; Edmunds et al. 2014; Alvarez-Filip et al. 2015). However, we still lack temporal data for lesser-studied regions in the Indo-Pacific and the Red Sea (Beruman et al. 2013; but see Edmunds et al. 2014, McClanahan et al. 2014 and Beldade et al. 2015 for recent comparisons in French Polynesia and the Western Indian Ocean). Data from these lesser-studied regions will help fill crucial gaps in our understanding of the global patterns driving coral reef decline.

Several physical properties of reef habitats are associated with increased resilience and/or biodiversity including reef zone, depth, area, structural complexity and shelter availability (e.g. Bellwood and Hughes 2001; Ménard et al. 2012; Graham and Nash 2013; Graham et al. 2014; Graham et al. 2015). In addition, biotic factors such as live coral cover and the presence/absence of key functional groups or organisms are important determinants of fish abundance and diversity (e.g. Bshary 2003; Grutter, Murphy \& Choat, 2003; Jones et al., 2004). Specifically, the long-term presence of the ectoparasite-eating cleaner wrasse, Labroides dimidiatus, is associated with increased growth, condition and abundance of its "client" fishes (Grutter, Murphy \& Choat, 2003; Clague et al., 2011; Waldie et al., 2011; Bonaldo, Hoey \& Bellwood, 2014, Fig. 1).

However, few studies explicitly include cleaner wrasse abundance alongside other biotic and abiotic factors when evaluating predictors of reef fish species richness and abundance.

We surveyed live coral cover and coral reef fishes in 1997 and again in 2007 on 47 patch reefs at Mersa Bereika, Ras Mohammed National Park, Egypt, to (1) assess natural changes in coral cover and fish species abundance and richness in an undisturbed reef system between two points in time and (2) identify important biotic and abiotic predictors of fish abundance and species richness using reef patches as replicates. 


\section{Materials and methods}

71

Study site

Ras Mohammed National Park is located at the southern tip of the Sinai Peninsula in the Red Sea, Egypt. Established as a protected area in 1983, the park spans an area of $480 \mathrm{~km}^{2}$ including coral reef, coastline, mangrove and desert habitats (SEAM 2005). Threats to the area include shipping traffic, oil spills, invasive species (e.g. the crown-of-thorns starfish, Acanthaster planci), climate change (e.g. increased temperatures causing coral bleaching), and tourism (Ormond et al. 1997; SEAM 2005; Tilot et al. 2008). However, Mersa Bereika (27²7'23.9"N, $\left.34^{\circ} 13^{\prime} 02.8^{\prime \prime} \mathrm{E}\right)$, located inside the Ras Mohammed National Park, is a designated research area, which restricts human activity occurring in the region and was closed to tourists during the study period. No natural or human disturbance is known to have occurred in the study area during the ten years between surveys. An outbreak of $A$. planci in 1998 affected some of the reefs in Ras Mohammed National Park. However, the Egyptian Environmental Affairs Agency reacted quickly to the threat, thus minimizing the impact at this site (PERSGA/GEF 2003). No A. planci were observed on the patch reefs in Mersa Bereika throughout the outbreak during surveys by RB in 1998. Similarly, the 1998 global coral bleaching event, which caused substantial damage in the southern Red Sea and Gulf of Aden, did not affect the northern Red Sea (Kobt et al. 2004). Permission to carry out research in Mersa Bereika was granted to RB by the Egyptian Environmental Affairs Agency, locally verified by the authorities at Ras Mohammed National Park.

Habitat surveys 
Mersa Bareika is a narrow fringing reef along the coast of a well-protected bay (Fig. 1).

92

Sand enters the water through wadis channels that flood during the rainy season, creating small patch reefs separated by at least $5 \mathrm{~m}$ of sand. Forty seven patch reefs (depth $0.68 \mathrm{~m}$ to $7.57 \mathrm{~m}$ ) spanning $450 \mathrm{~m}$ of shoreline were surveyed in November 1997 (see Bshary 2003) and again between September and November 2007 (Fig. 2, electronic supplementary material ESM Table S1). Average depth below the surface was estimated for each patch with a dive computer. Patch volume was estimated following methods described in Bshary (2003). Maximum patch length, width, and average height above the substrate were used to calculate volume according the closest geometrical shape of the patch (e.g. rectangle, ellipse). Percentage live coral cover on each patch was estimated using a modified line-intercept method (English, Wilkinson \& Baker, 1997): a transect tape was laid out across the longest section of each patch and coral cover estimated as the proportion of the transect tape that was laid over live coral. The tape was then set perpendicular to this axis, across the widest area of the patch, and the process repeated. The total percentage area of live coral cover was calculated as the mean of these two measures. The total percentage of holes and caves on each patch was also estimated in this way. Holes were defined as small cavities (typically $1-3 \mathrm{~cm}$ wide) on the surface of the reef matrix (excluding spaces in between coral). Caves were defined as openings at the base of the reef where the reef matrix connected to the substrate.

\section{Fish surveys}

Coral reef fishes were categorized into four groups depending on their movement patterns and habitat use (Table S2; Bshary 2001). Resident fishes have small home ranges restricted to a single patch reef and include damselfishes (Pomacentridae), cardinalfishes (Apogonidae), squirrelfishes (Holocentridae) and some wrasses (Labridae). Visitors have larger home ranges 
114 that overlap several patches, and include parrotfishes (Scaridae), goatfishes (Mullidae) and

115 fusiliers (Caesionidae). Butterflyfishes (Chaetodontidae) remain on one patch for long periods

116 (hours to days) but also move between patches, and were considered facultative visitors (i.e.

117 intermediate home ranges). Species that we could not classify into any of the three categories

118 were categorized as undetermined (e.g. Cyrrithidae, Tetraodontidae).

Reef fish abundance and species richness were surveyed by two SCUBA divers three times in 1997 and five times in 2007, at two week intervals. One observer identified species and recorded their abundance at each patch. The second diver also recorded species' identity to ensure the primary observer had not missed a species. Upon arrival at a patch, observers recorded fishes in the following order: visitors, facultative visitors, residents and undetermined. The abundance of species occurring in shoals or schools was estimated in multiples of ten. Fishes that swam to patches after the count had begun were not recorded. Cryptic species including most blennies (Blenniidae) and gobies (Gobiidae) were excluded from the surveys except for the scale-eating blenny (Plagiotremus tapeinosoma), the bluestriped blenny (Plagiotremus rhinorhynchos), the mimic blenny (Aspidontus taeniatus), and the blackfin dartfish (Ptereleotris microlepis). Species that primarily occupy sandy areas such as pipefishes (Syngnathidae) and lizardfishes (Synodontidae) were also excluded.

131

\section{Statistical analyses}

We examined differences in percent live coral cover between 1997 and 2007 on the 47 patches using a paired t-test. Percent live coral cover was logit transformed (Warton and Hui 2010). We used the Information Theoretic approach (Burnham and Anderson 2002; Johnson and Omland 2004; Grueber et al. 2011) to determine which variables best explained variation in fish 
136 abundance (number of individuals) and species richness (number of species) among patch reefs

137 and years. Response variables were averaged across fish surveys within year. Therefore, the data

138 were not Poisson distributed or zero inflated. Two full models were constructed using general

139 linear mixed-effects models (LMM; lmer function in R). Model assumptions were checked with

140 plots of residuals vs. fitted values and qqplots of residuals for fixed and random effects. Fish

141 abundance was log transformed to meet model assumptions. Seven predictor variables were

142 included in each model: survey year, depth below surface, patch volume, percent live coral

143 cover, percent caves, percent holes and cleaner wrasse abundance. Cleaner wrasse abundance

144 was not included in the fish abundance counts. We graphically examined all two-way

145 interactions and excluded those that had no apparent effect on the response variables for model

146 simplicity and parsimony following recommendations in Burnham and Anderson (2002). We

147 examined non-linear relationships using pairs plots and plots of generalized additive models

148 (GAM). Quadratic terms were included where necessary. Patch ID was included as a random

149 factor in both models and quadratic terms were included where necessary. Continuous predictors

150 were $\mathrm{z}$-standardized (mean=0, SD=1) and a correlation plot used to check for collinearity. All

151 correlation coefficients were $<0.35$. See ESM Table S3 and S4 for details of the main effects and

152 interaction terms included in the full models.

We used the Akaike Information Criterion modified for small sample sizes (AICc) to select the best candidate models for each response variable with the "dredge" function in the $\mathrm{R}$ package MuMIn. We performed model averaging using the "model.avg" function (MuMIn) when the normalized Akaike weight values $\left(w_{\text {im }}\right)$ of the best models were $<0.9$ (Burnham and Anderson 2002). The confidence set of candidate models selected for model averaging included all models for which the $w_{\text {im }}$ fell within $10 \%$ of the maximum normalized weight, suggesting that 
159 these models had substantial support in explaining the data (Burnham and Anderson 2002). We

160 calculated the marginal $\mathrm{R}^{2}$ (variance explained by the fixed factors; $\mathrm{R}^{2} \mathrm{GLMM}(\mathrm{m})$ ) and conditional

$161 \mathrm{R}^{2}$ (variance explained by the fixed and random factors; $\mathrm{R}^{2}{ }_{\mathrm{GLMM}(\mathrm{c})}$ ) following Nakagawa and

162 Schielzeth (2013). All analyses were done in R 3.1.2 (R Development Core Team 2014). The

163 data and code for this study are deposited in the public respository figshare (Wagner et al. 2015)

164 following best practices outlined in White et al. (2013).

165

166

167

168

169

170

\section{Results and Discussion}

There was no difference in percent live coral cover on the 47 patches surveyed in 1997 and $2007\left(\mathrm{t}_{46}=1.48, p=0.15\right.$; Table 1$)$. This pattern was not driven by a shift to soft corals as documented in Tilot et al. (2008): no information is available for 1997, but soft corals made up only a small proportion of live corals in 2007 , i.e. $0-10 \%$ on 41 out of 47 patches.

Eighteen and thirty models had support in explaining fish abundance and species richness on patch reefs based on AICc scores, respectively (Table 2, ESM Table S3, S4). In both cases, fixed factors explained over 60 percent of the variance; this percentage exceeded $80 \%$ when accounting for both fixed and random factors (Table 2).

We found no marked difference in fish abundance in 1997 and 2007 (Tables 1, 2a). The presence of caves and live coral cover were strongly, positively related to fish abundance, and the effect of live coral cover was stronger when the presence of caves was high (ESM Fig. S1). Patch volume also had a positive (saturating) effect on fish abundance but only when caves were abundant (ESM Fig. S2). These findings support previous studies which stress the importance of shelters and live coral in positively influencing fish abundance (Jones et al. 2004; Ménard et al. 2012; Graham and Nash 2013). We also found a positive correlation between fish abundance and 
182 cleaner wrasse abundance, although the confidence interval of this estimate overlapped zero 183 (Table 2a).

Across all patches, a total of 86 species from 24 fish families were recorded in 1997, and

185

186

187

188

118 species from 29 fish families in 2007 (Table S2). This overall trend was reflected at the patch level by a slight increase in fish species richness between years (Tables 1, 2b). Patch species richness was positively related to live coral cover, caves, holes, patch volume, and the presence of cleaner fish (Table 2b, ESM Fig. S3). Similar to fish abundance, the relationship between live coral cover and species richness was stronger when more caves were present, and the positive (saturating) effect of patch size (volume) was greater when caves were abundant (ESM Fig. S4). Patch volume was also positively related to species richness and the strength of this relationship increased as the presence of holes increased (ESM Fig. S5). Live coral cover was more strongly related to species richness as depth increased (ESM Fig. S6) perhaps as a result of an increase in the number of resident and/or coral-dependent species at greater depths. Importantly, cleaner fish abundance was as important as live coral cover, caves and patch volume at predicting fish species richness on patches (Table $2 b$ ).

Recent studies have identified a causal link between cleaner wrasse presence and client fish diversity. Short and long-term experimental removal of L. dimidiatus on patch reefs in Egypt and Australia led to decreases in mean fish size, species abundance and/or richness of fishes on reefs without cleaners (Bshary 2003; Waldie et al. 2011). Our results support these findings, and suggest that natural variation in cleaner wrasse abundance on reefs is also related to fish species richness and, to a lesser extent, abundance. The strong effect of cleaner wrasses on coral reef fish communities is remarkable given that cleaners are small $(<15 \mathrm{~cm})$ and uncommon relative to 
204 other reef dwellers, suggesting that positive interactions among reef fish species are important,

205 but often overlooked, components of reef communities (Grutter and Irving 2007).

206 Despite increasing protection and awareness of the need to conserve coral reef habitats,

207 studies suggest that the global decline in coral reef health has been rapid, severe and may be

208 irreversible (Hughes 1994; Veron et al. 2009; Hoegh-Guldberg and Bruno 2010). Yet, some

209 near-pristine reef habitats remain, and temporal monitoring of these undisturbed areas provides

210 crucial baselines, which can help inform conservation planning and management of degraded

211 reefs (Knowlton and Jackson 2008). Our results provide crucial data on the status of a series of

212 patch reefs in the Red Sea, a region that remains understudied despite a well-developed tourist

213 industry (Beruman et al. 2013). Our temporal comparison revealed that undisturbed patch reefs

214 in the Red Sea had similar values of live coral cover and fish species richness and abundance in

2151997 as in 2007 according to our point-in-time sampling. Our results also underscore the

216 importance of physical reef characteristics, such as patch size and shelter availability, in addition

217 to biotic characteristics, such as live coral cover and cleaner wrasse abundance, in supporting

218 reef fish assemblages. These reef properties should thus be considered in future management

219 plans aimed at promoting increases in coral reef fish abundance and richness.

\section{Acknowledgements}

222 We thank the authorities at Ras Mohammed National Park and the Egyptian Environmental Affairs Agency for permission to conduct this research, L. Chapuis, I. Riepl, Abdallah, Raffia and Hamoo for field and logistic support, R. Slobodeanu and K. Turgeon for statistical advice, and S. Meyer, C. Strübin, A. Pinto, and R. Bergmüller for helpful discussion, and three anonymous reviews for comments on a previous version of this manuscript. 


\section{References}

229

230

231

232

233

234

235

236

237

238

239

240

241

242

243

244

245

246

247

248

249

Alvarez-Filip L, Paddack MJ, Collen B, Robertson DR, Côté IM. 2015. Simplification of Caribbean reef-fish assemblages over decades of coral reef degradation. PLoS ONE 10:e0126004. DOI: 10.1371/journal.pone.0126004.

Beldade R, Mills SC, Claudet J, Côté IM. 2015. More coral, more fish? Contrasting snapshopt from a remote Pacific atoll. PeerJ 3:e745. DOI: 10.7717/peerj.745.

Bellwood DR, Hughes TP. 2001. Regional-scale assembly rules and biodiversity of coral reefs. Science 292:1532-1534.

Bellwood DR, Hughes TP, Folke C, Nystrom M. 2004. Confronting the coral reef crisis. Nature 429:827-833.

Berumen ML, Hoey AS, Bass WH, Bouwmeester J, Catania D, Cochran JEM, Khalil MT, Miyake S, Mughal MR, Spaet JLY, Saenz-Agudelo P. 2013. The status of coral reef ecology research in the Red Sea. Coral Reefs 32:737-748. DOI: 10.1007/s00338-013$1055-8$

Bonaldo RM, Hoey AS, Bellwood DR. 2014. The ecosystem roles of parrotfishes on tropical reefs. In: Hughes RN, Hughes DJ, Smith IP, eds. Oceanography and Marine Biology: An Annual Review. Taylor and Francis, 81-132.

Bshary R. 2001. The cleaner fish market. In: Noë R, Van Hooff JARAM, Hammerstein P. eds. Economics in nature. Cambridge University Press, Cambridge, pp146-172.

Bshary R. 2003. The cleaner wrasse, Labroides dimidiatus, is a key organism for reef fish diversity at Ras Mohammed National Park, Egypt. Journal of Animal Ecology 72:169176. 
250

251

252

253

254

255

256

257

258

259

260

261

262

263

264

265

266

267

268

269

270

Burnham K, Anderson D. 2002. Model selection and multimodal inference: a practical information-theoretic approach. Springer, New York.

Clague GE, Cheney KL, Goldizen AW, McCormick MI, Waldie PA, Grutter AS. 2011. Longterm cleaner fish presence affects growth of a coral reef fish. Biology Letters 7:863-865. DOI: $10.1098 / \mathrm{rsbl} .2011 .0458$.

De'ath G, Fabricius KE, Sweatman H, Puotinen M. 2012. The 27-year decline of coral cover on the Great Barrier Reef and its causes. Proceedings of the National Academy of Sciences USA 109:17995-17999. DOI: 10.1073/pnas.1208909109.

Edmunds PJ, Adjeroud M, Baskett ML, Baums IB, Budd AF, Carpenter RC, Fabina NS, Fan TY, Franklin EC, Gross K, Han X, Jacobson L, Klaus JS, McClanahan TR, O'Leary JK, van Oppen MJH, Pochon X, Putnam HM, Smith TB, Stat M, Sweatman H, van Woesik R, Gates RD. 2014. Persistence and Change in Community Composition of Reef Corals through Present, Past, and Future Climates. PLoS ONE 9:e107525. DOI: 10.1371/journal.pone.0107525.

English S, Wilkinson C, Baker V. 1997. Survey manual for tropical marine resources. Australian Institute of Marine Science, Townsville, Australia.

Gardner TA, Cote IM, Gill JA, Grant A, Watkinson AR. 2005. Hurricanes and Caribbean coral reefs: Impacts, recovery patterns, and role in long-term decline. Ecology 86:174-184. DOI: $10.1890 / 04-0141$.

Graham NAJ, Nash KL. 2013. The importance of structural complexity in coral reef ecosystems. Coral Reefs 32:315-326. DOI: 10.1007/s00338-012-0984-y. 
271 Graham NAJ, Chong-Seng KM, Huchery C, Januchowski-Hartley FA, Nash KL. 2014. Coral

272

273

274

275

276

277

278

279

280

281

282

283

284

285

286

287

288

289

290

291

292 reef community composition in the context of disturbance history on the Great Barrier Reef, Australia. PLoS ONE 9:e101204. DOI: 10.1371/journal.pone.0101204.

Graham NAJ, Jennings S, Macneil MA, Mouillot D, Wilson SK. 2015. Predicting climate-driven regime shifts versus rebound potential in coral reefs. Nature 5181:94-97. DOI: 10.1038/nature14140.

Grueber CE, Nakagawa S, Laws RJ, Jamieson IG. 2011. Multimodel inference in ecology and evolution: challenges and solutions. Journal of Evolutionary Biology 24:699-711. DOI: 10.1111/j.1420-9101.2010.02210.x.

Grutter AS, Irving AD. 2007. Positive interactions in marine communities. In: Connell SDG, B.M. ed. Marine Ecology. Oxford University Press, Melbourne, pp110-137.

Grutter AS, Murphy JM, Choat JH. 2003. Cleaner fish drives local fish diversity on coral reefs. Current Biology 13:64-67. DOI: 10.1016/S0960-9822(02)01393-3.

Hasler H, Ott JA. 2008. Diving down the reefs? Intensive diving tourism threatens the reefs of the northern Red Sea. Marine Pollution Bulletin 56:1788-1794. DOI: 10.1016/j.marpolbul.2008.06.002.

Hoegh-Guldberg O, Bruno JF. 2010. The impact ofclimate change on the world's marine ecosystems. Science 328:1523-1528. DOI: 10.1126/science. 1189930.

Hughes TP. 1994. Catastrophes, phase shifts, and large-scale degradation of a Caribbean coral reef. Science 265:1547-1551.

Hughes TP, Connell JH (1999) Multiple stressors on coral reefs: A long-term perspective. Limnolology Oceanogrraphy 44:932-940. 
293 Hughes TP, Graham NAJ, Jackson JBC, Mumby PJ, Steneck RS. 2010. Rising to the challenge

294 of sustaining coral reef resilience. Trends in Ecoloy and Evolution 25:633-642. DOI:

295

296

297

298

299

300

301

302

303

304

305

306

307

308

309

310

311

312

313

314

315 10.1016/j.tree.2010.07.011.

Johnson JB, Omland KS. 2004. Model selection in ecology and evolution. Trends in Ecology \& Evolution 19:101-108. DOI: 10.1016/j.tree.2003.10.013.

Jones GP, McCormick MI, Srinivasan M, Eagle JV. 2004. Coral decline threatens fish biodiversity in marine reserves. Proceedings of the National Academy of Sciences USA. $101: 8251-8253$

Kobt M, Abdulaziz M, Al-Agwan Z, Alshaikh K, Al-Yami H, Banajah A, Devantier L, Eisinger M, Eltayeb M, Hassan M, Heisse G, Howe S, Kemp J, Klaus R, Krupp F, Mohamed N, Rouphael T, Turner J, Zajonz U. 2004. Status of coral reefs in the Red Sea and the Gulf of Aden in 2004. In: Wilkinson C. ed. Status of coral reefs of the world: 2004. Australian Institute of Marine Science, Townsville, QLD Australia, pp137-154.

Knowlton N, Jackson JBC. 2008. Shifting baselines, local impacts, and global change on coral reefs. PLoS Biology 6:e54. DOI: 10.1371/journal.pbio.0060054.

McClanahan TR, Ateweberhan M, Darling ES, Graham NAJ, Muthiga NA. 2014. Biogeography and change among regional coral communities across the Western Indian Ocean. PLoS ONE 9: e93385. DOI:10.1371/journal.pone.0093385.Ménard A, Turgeon K, Roche DG, Binning SA, Kramer DL. 2012. Shelters and their use by fishes on fringing coral reefs. PLoS ONE 7:e38450. DOI: 10.1371/journal.pone.0038450.

Nakagawa S, Schielzeth H. 2013. A general and simple method for obtaining R2 from generalized linear mixed-effects models. Methods in Ecology and Evolution 4:133-142. DOI:10.1111/j.2041-210x.2012.00261.x. 
316 Ormond R, Hassan O, Medio D, Pearson M, Salem M. 1997. Effectiveness of coral protection programmes in the Ras Mohammed National Park, Egyptian Red Sea. Proceedings of the 8th International Coral Reef Symposium 2:1931-1936.

319 Pandolfi JM, Bradbury RH, Sala E, Hughes TP, Bjorndal KA, Cooke RG, McArdle D, McClenachan L, Newman MJH, Paredes G, Warner RR, Jackson JBC. 2003. Global trajectories of the long-term decline of coral reef ecosystems. Science 301:955-958. DOI:

PERSGA/GEF. 2003. Coral reefs in the Red Sea and Gulf of Aden. Surveys 1990 to 2000 summary and recommendations. The Regional Organization for the Conservation of the Environment of the Red Sea and Gulf of Aden and the Global Environment Facility; Technical Series No 7, Jeddah, Saudi Arabia.

R Development Core Team. 2014. R: A language and environment for statistical computing. R Foundation for Statistical Computing, Vienna, Austria, ISBN 3-900051-07-0, http://www.R-project.org.

SEAM. 2005. South Sinai environmental profile. Support for Environmental Assessment and Management Program (SEAM); South Sinai Department for International Development (DFID), UK

Tilot V, Leujak W, Ormond RFG, Ashworth JA, Mabrouk A. 2008. Monitoring of South Sinai coral reefs: influence of natural and anthropogenic factors. Aquatic Conservation 18:1109-1126. DOI: 10.1002/aqc.942.

Veron JEN, Hoegh-Guldberg O, Lenton TM, Lough JM, Obura DO, Pearce-Kelly P, Sheppard CRC, Spalding M, Stafford-Smith MG, Rogers AD. 2009. The coral reef crisis: The 
critical importance of < 350ppm $\mathrm{CO}_{2}$. Marine Pollution Bulletin 58:1428-1436. DOI: 10.1016/j.marpolbul.2009.09.009.

Wagner ELE, Roche D, Binning S, Wismer S, Bshary R. 2015. Temporal comparison and predictors of community composition on undisturbed coral reef patches. figshare. DOI:10.6084/m6089.figshare.1335775.

Waldie PA, Blomberg SP, Cheney KL, Goldizen AW, Grutter AS. 2011. Long-term effects of the cleaner fish Labroides dimidiatus on coral reef fish communities. PLoS ONE 6:e21201. DOI: 10.1371/journal.pone.0021201.

Warton DI, Hui FKC. 2010. The arcsine is asinine: the analysis of proportions in ecology. Ecology 92:3-10. DOI: 10.1890/10-0340.1. make it easier to (re) use your data. Ideas in Ecology and Evolution 6:1-10. DOI: 10.4033/iee.2013.6b.6.f. 
351 Tables

352 Table 1. Mean and mean paired difference ( \pm one standard error) for percent live coral cover,

353 fish abundance and fish species richness on 47 patch reefs at Ras Mohammed National Park,

354 Egypt, in 1997 and in 2007.

355

\begin{tabular}{lcccc}
\hline Year & Coral cover & Abundance & $\log ($ Abundance) & Richness \\
\hline 2007 & $22.5 \pm 1.8$ & $109.9 \pm 15.9$ & $1.86 \pm 0.06$ & $20.5 \pm 1.3$ \\
1997 & $24.9 \pm 1.8$ & $147.7 \pm 22.2$ & $1.96 \pm 0.07$ & $18.6 \pm 1.1$ \\
Paired difference & $-2.4 \pm 2.0$ & $-37.9 \pm 12.8$ & $-0.10 \pm 0.04$ & $2.0 \pm 0.6$ \\
\hline
\end{tabular}

356

357

358

Table 2. Predictors and interaction terms included in the best models explaining variation in (A)

359

fish abundance and (B) species richness among patch reefs ( $\mathrm{n}=47)$ and years (1997 vs. 2007).

360 The model averaged parameters estimates $(\beta)$, unconditional standard errors (SE), 95\%

361 confidence interval $(95 \% \mathrm{CI})$, and the normalized Akaike weight $\left(w_{\text {ip }}\right)$ for each predictor are

362 shown. Also included is the number of models (Models) in which predictors were included and

363 marginal $\left[\mathrm{R}^{2}{ }_{\mathrm{GLMM}(\mathrm{m})}\right]$ and conditional $\left[\mathrm{R}^{2}{ }_{\mathrm{GLMM}(\mathrm{c})}\right] \mathrm{R}^{2}$ values for the mixed model (LMM) with

364 predictors identified as important. Predictors are in order of importance $\left(w_{\mathrm{ip}}\right)$; those for which the

$36595 \%$ CI does not overlap zero are indicated in bold. All models include a constant. See ESM for

366 detailed tables.

367

\begin{tabular}{lccccc}
\hline (A) Fish abundance & & & & & \\
\hline Predictor & $\boldsymbol{\beta}$ & SE & $\mathbf{9 5 \%}$ CI & $\boldsymbol{w}_{\text {ip }}$ & Models \\
\hline Intercept & 4.85 & 0.15 & 4.56 to 5.15 & 1.00 & 18 \\
Percent caves (PC) & $\mathbf{0 . 3 5}$ & $\mathbf{0 . 1 2}$ & $\mathbf{0 . 1 2}$ to $\mathbf{0 . 5 8}$ & $\mathbf{1 . 0 0}$ & $\mathbf{1 8}$ \\
Percent live coral cover (PLCC) & $\mathbf{0 . 2 3}$ & $\mathbf{0 . 0 6}$ & $\mathbf{0 . 1 1}$ to $\mathbf{0 . 3 6}$ & $\mathbf{1 . 0 0}$ & $\mathbf{1 8}$ \\
Patch volume (PV) & $\mathbf{1 . 0 5}$ & $\mathbf{0 . 1 4}$ & $\mathbf{0 . 7 8}$ to $\mathbf{1 . 3 2}$ & $\mathbf{1 . 0 0}$ & $\mathbf{1 8}$ \\
PV & $\mathbf{- 0 . 4 2}$ & $\mathbf{0 . 1 1}$ & $\mathbf{- 0 . 6 3}$ to $\mathbf{- 0 . 2 1}$ & $\mathbf{1 . 0 0}$ & $\mathbf{1 8}$ \\
PC:PLCC & $\mathbf{0 . 2 1}$ & $\mathbf{0 . 0 6}$ & $\mathbf{0 . 0 8}$ to $\mathbf{0 . 3 3}$ & $\mathbf{1 . 0 0}$ & $\mathbf{1 8}$
\end{tabular}




\begin{tabular}{|c|c|c|c|c|c|}
\hline PC:PV & 0.41 & 0.13 & 0.16 to 0.66 & 1.00 & 18 \\
\hline L. dimidiatus abundance (Ldim) & 0.10 & 0.06 & -0.01 to 0.22 & 0.63 & 11 \\
\hline Year & -0.16 & 0.09 & -0.33 to 0.01 & 0.57 & 9 \\
\hline Percent Holes (PH) & -0.03 & 0.08 & -0.18 to 0.13 & 0.31 & 10 \\
\hline Depth & -0.02 & 0.08 & -0.18 to 0.15 & 0.15 & 4 \\
\hline PH:Ldim & 0.08 & 0.05 & -0.02 to 0.17 & 0.09 & 3 \\
\hline PC:PH & 0.09 & 0.09 & -0.09 to 0.28 & 0.08 & 4 \\
\hline \multicolumn{6}{|l|}{$\mathrm{R}_{\mathrm{GLMM}(\mathrm{m})}^{2}=0.64, \mathrm{R}_{\mathrm{GLMM}(\mathrm{c})}=0.82$} \\
\hline \multicolumn{6}{|l|}{ (B) Fish species richness } \\
\hline Predictor & $\beta$ & SE & $95 \% \mathrm{CI}$ & $w_{\text {ip }}$ & Models \\
\hline Intercept & 20.44 & 0.98 & 18.51 to 22.37 & 1.00 & 30 \\
\hline Percent live coral cover (PLCC) & 1.23 & 0.41 & 0.44 to 2.03 & 1.00 & 30 \\
\hline L. dimidiatus abundance (Ldim) & 1.75 & 0.39 & 0.99 to 2.52 & 1.00 & 30 \\
\hline Year & 2.87 & 0.59 & 1.71 to 4.03 & 1.00 & 30 \\
\hline Patch volume (PV) & 8.34 & 0.92 & 6.53 to 10.15 & 1.00 & 30 \\
\hline $\mathbf{P V}^{2}$ & -2.48 & 0.76 & -3.97 to -1.00 & 1.00 & 30 \\
\hline Percent caves $(\mathrm{PC})$ & 1.68 & 0.78 & 0.15 to 3.20 & 0.96 & 29 \\
\hline PC:PV & 2.21 & 0.82 & 0.61 to 3.81 & 0.91 & 26 \\
\hline PC:PLCC & 0.88 & 0.40 & 0.10 to 1.67 & 0.77 & 21 \\
\hline Depth & -0.77 & 0.54 & -1.83 to 0.29 & 0.70 & 23 \\
\hline Percent holes $(\mathrm{PH})$ & 0.71 & 0.53 & -0.33 to 1.74 & 0.62 & 18 \\
\hline PH:PV & 1.60 & 0.65 & 0.33 to 2.87 & 0.55 & 14 \\
\hline PLCC:Depth & 0.97 & 0.45 & 0.09 to 1.85 & 0.48 & 15 \\
\hline PC:Ldim & 0.69 & 0.70 & -0.68 to 2.05 & 0.21 & 9 \\
\hline PH:Ldim & 0.20 & 0.33 & -0.47 to 0.84 & 0.11 & 5 \\
\hline $\mathrm{R}_{\mathrm{GLMM}(\mathrm{m})}^{2}=0.81, \mathrm{R}^{2}{ }_{\mathrm{GLMM}(\mathrm{c})}=0.90$ & & & & & \\
\hline
\end{tabular}




\section{Figures}

370 Fig. 1 The cleaner wrasse, Labroides dimidiatus, removes ectoparasites from the surface of a

371 'client' reef fish (Photo: L. dimidiatus cleaning an anthias, Pseudanthias squamipinnis, Red Sea,

372 S. Gingins). 


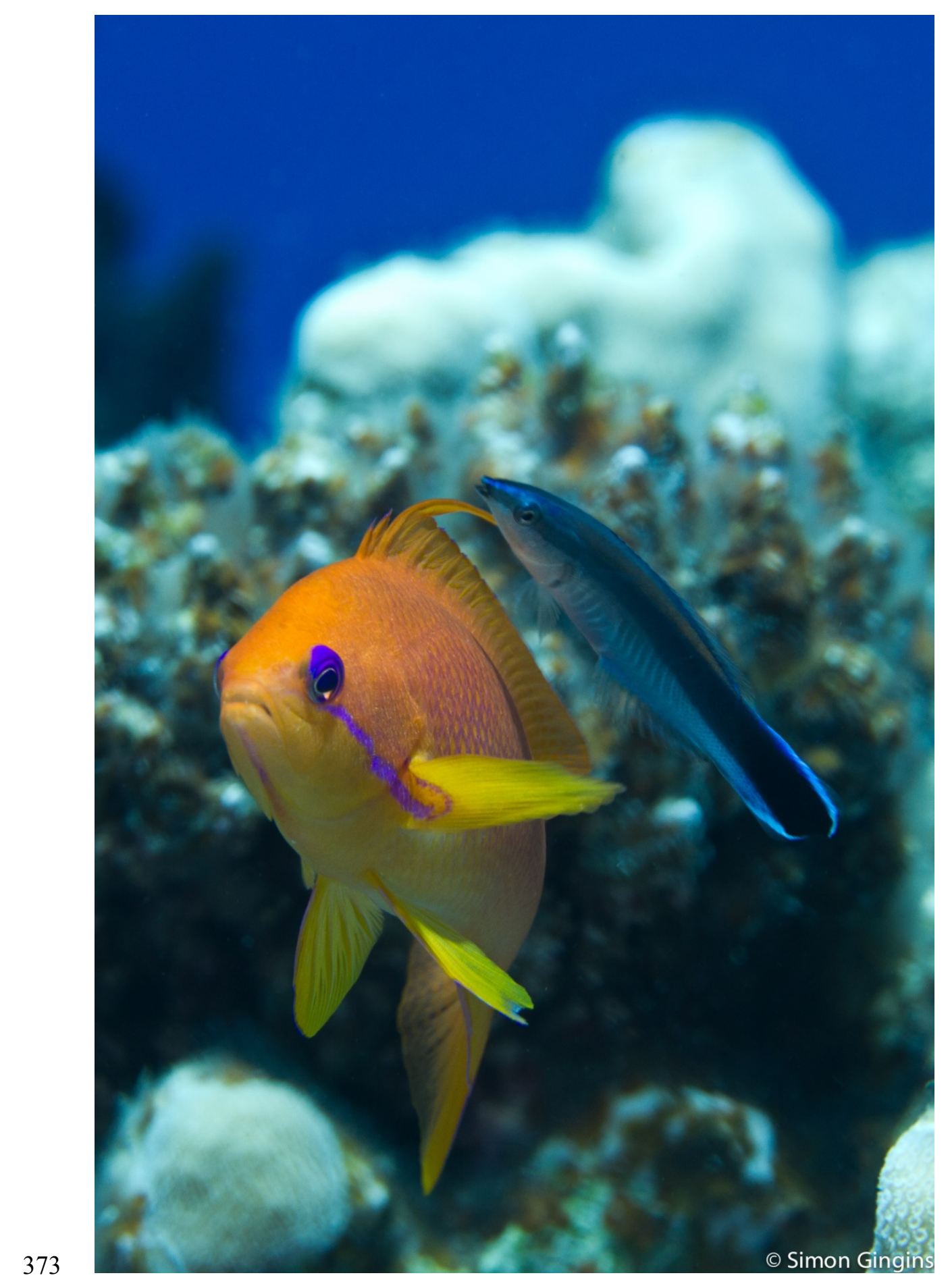

374 Fig. 2 Map of the patch reefs and study area at Mersa Bareika, Ras Mohammed National Park,

375 Egypt $\left(27^{\circ} 47^{\prime} 23.9^{\prime \prime} \mathrm{N}, 34^{\circ} 13^{\prime} 02.8^{\prime \prime} \mathrm{E}\right)$. The dotted line defines the park boundaries. 


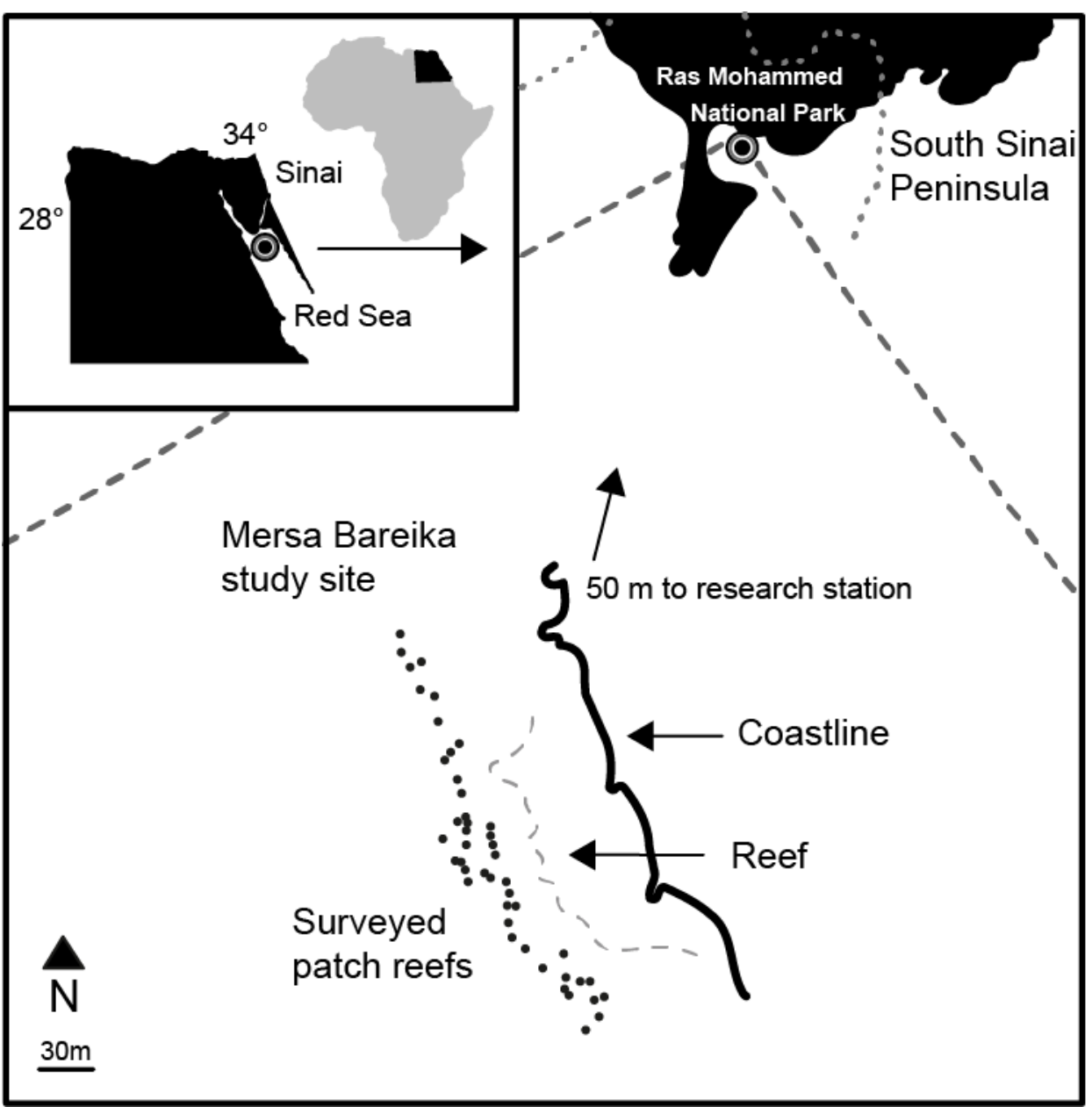




\section{Table $\mathbf{1}$ (on next page)}

Comparison of patch characteristics between years

Table 1. Mean and mean paired difference ( \pm one standard error) for percent live coral cover, fish abundance and fish species richness on 47 patch reefs at Ras Mohammed National Park, Egypt, in 1997 and in 2007. 
1 Table 1. Mean and mean paired difference ( \pm one standard error) for percent live coral cover,

2 fish abundance and fish species richness on 47 patch reefs at Ras Mohammed National Park,

3 Egypt, in 1997 and in 2007.

4

\begin{tabular}{lcccc}
\hline Year & Coral cover & Abundance & $\log$ (Abundance) & Richness \\
\hline 2007 & $22.5 \pm 1.8$ & $109.9 \pm 15.9$ & $1.86 \pm 0.06$ & $20.5 \pm 1.3$ \\
1997 & $24.9 \pm 1.8$ & $147.7 \pm 22.2$ & $1.96 \pm 0.07$ & $18.6 \pm 1.1$ \\
Paired difference & $-2.4 \pm 2.0$ & $-37.9 \pm 12.8$ & $-0.10 \pm 0.04$ & $2.0 \pm 0.6$ \\
\hline
\end{tabular}

5

6 


\section{Table 2 (on next page)}

Model selection results

Table 2. Predictors and interaction terms included in the best models explaining variation in (A) fish abundance and (B) species richness among patch reefs $(n=47)$ and years (1997 vs. 2007). The model averaged parameters estimates ( $\beta$ ), unconditional standard errors (SE), 95\% confidence interval $(95 \% \mathrm{Cl})$, and the normalized Akaike weight $\left(w_{\mathrm{ip}}\right)$ for each predictor are shown. Also included is the number of models (Models) in which predictors were included and marginal $\left[R_{G L M M(m)}^{2}\right]$ and conditional $\left[R_{G L M M(c)}^{2} R^{2}\right.$ values for the mixed model (LMM) with predictors identified as important. Predictors are in order of importance $\left(w_{\mathrm{ip}}\right)$; those for which the $95 \% \mathrm{Cl}$ does not overlap zero are indicated in bold. All models include a constant. See ESM for detailed tables. 
1 Table 2. Predictors and interaction terms included in the best models explaining variation in (A)

2 fish abundance and (B) species richness among patch reefs ( $n=47)$ and years (1997 vs. 2007).

3 The model averaged parameters estimates $(\beta)$, unconditional standard errors (SE), 95\%

4 confidence interval $(95 \% \mathrm{CI})$, and the normalized Akaike weight $\left(w_{\text {ip }}\right)$ for each predictor are

5 shown. Also included is the number of models (Models) in which predictors were included and

6 marginal $\left[\mathrm{R}^{2}{ }_{\mathrm{GLMM}(\mathrm{m})}\right]$ and conditional $\left[\mathrm{R}^{2}{ }_{\mathrm{GLMM}(\mathrm{c})}\right] \mathrm{R}^{2}$ values for the mixed model (LMM) with

7 predictors identified as important. Predictors are in order of importance $\left(w_{\mathrm{ip}}\right)$; those for which the

$895 \%$ CI does not overlap zero are indicated in bold. All models include a constant. See ESM for

9 detailed tables.

10

\begin{tabular}{|c|c|c|c|c|c|}
\hline \multicolumn{6}{|l|}{ (A) Fish abundance } \\
\hline Predictor & $\beta$ & SE & 95\% CI & $w_{\text {ip }}$ & Models \\
\hline Intercept & 4.85 & 0.15 & 4.56 to 5.15 & 1.00 & 18 \\
\hline Percent caves $(\mathrm{PC})$ & 0.35 & 0.12 & 0.12 to 0.58 & 1.00 & 18 \\
\hline Percent live coral cover (PLCC) & 0.23 & 0.06 & 0.11 to 0.36 & $\mathbf{1 . 0 0}$ & 18 \\
\hline Patch volume (PV) & 1.05 & 0.14 & 0.78 to 1.32 & 1.00 & 18 \\
\hline $\mathbf{P V}^{2}$ & -0.42 & 0.11 & -0.63 to -0.21 & 1.00 & 18 \\
\hline PC:PLCC & 0.21 & 0.06 & 0.08 to 0.33 & $\mathbf{1 . 0 0}$ & 18 \\
\hline PC:PV & 0.41 & 0.13 & 0.16 to 0.66 & $\mathbf{1 . 0 0}$ & 18 \\
\hline L. dimidiatus abundance (Ldim) & 0.10 & 0.06 & -0.01 to 0.22 & 0.63 & 11 \\
\hline Year & -0.16 & 0.09 & -0.33 to 0.01 & 0.57 & 9 \\
\hline Percent Holes $(\mathrm{PH})$ & -0.03 & 0.08 & -0.18 to 0.13 & 0.31 & 10 \\
\hline Depth & -0.02 & 0.08 & -0.18 to 0.15 & 0.15 & 4 \\
\hline PH:Ldim & 0.08 & 0.05 & -0.02 to 0.17 & 0.09 & 3 \\
\hline PC:PH & 0.09 & 0.09 & -0.09 to 0.28 & 0.08 & 4 \\
\hline
\end{tabular}

(B) Fish species richness

\begin{tabular}{lccccc}
\hline Predictor & $\boldsymbol{\beta}$ & SE & $\mathbf{9 5 \%}$ CI & $\boldsymbol{w}_{\text {ip }}$ & Models \\
\hline Intercept & 20.44 & 0.98 & 18.51 to 22.37 & 1.00 & 30 \\
Percent live coral cover (PLCC) & $\mathbf{1 . 2 3}$ & $\mathbf{0 . 4 1}$ & $\mathbf{0 . 4 4}$ to 2.03 & $\mathbf{1 . 0 0}$ & $\mathbf{3 0}$ \\
L. dimidiatus abundance (Ldim) & $\mathbf{1 . 7 5}$ & $\mathbf{0 . 3 9}$ & $\mathbf{0 . 9 9}$ to $\mathbf{2 . 5 2}$ & $\mathbf{1 . 0 0}$ & $\mathbf{3 0}$ \\
Year & $\mathbf{2 . 8 7}$ & $\mathbf{0 . 5 9}$ & $\mathbf{1 . 7 1}$ to $\mathbf{4 . 0 3}$ & $\mathbf{1 . 0 0}$ & $\mathbf{3 0}$ \\
Patch volume (PV) & $\mathbf{8 . 3 4}$ & $\mathbf{0 . 9 2}$ & $\mathbf{6 . 5 3}$ to $\mathbf{1 0 . 1 5}$ & $\mathbf{1 . 0 0}$ & $\mathbf{3 0}$ \\
PV & $\mathbf{- 2 . 4 8}$ & $\mathbf{0 . 7 6}$ & $\mathbf{- 3 . 9 7}$ to $-\mathbf{1 . 0 0}$ & $\mathbf{1 . 0 0}$ & $\mathbf{3 0}$ \\
Percent caves (PC) & $\mathbf{1 . 6 8}$ & $\mathbf{0 . 7 8}$ & $\mathbf{0 . 1 5}$ to 3.20 & $\mathbf{0 . 9 6}$ & $\mathbf{2 9}$
\end{tabular}




$\begin{array}{lccccc}\text { PC:PV } & \mathbf{2 . 2 1} & \mathbf{0 . 8 2} & \mathbf{0 . 6 1} \text { to } 3.81 & \mathbf{0 . 9 1} & \mathbf{2 6} \\ \text { PC:PLCC } & \mathbf{0 . 8 8} & \mathbf{0 . 4 0} & \mathbf{0 . 1 0} \text { to } 1.67 & \mathbf{0 . 7 7} & \mathbf{2 1} \\ \text { Depth } & -0.77 & 0.54 & -1.83 \text { to } 0.29 & 0.70 & 23 \\ \text { Percent holes }(\mathrm{PH}) & 0.71 & 0.53 & -0.33 \text { to } 1.74 & 0.62 & 18 \\ \text { PH:PV } & \mathbf{1 . 6 0} & \mathbf{0 . 6 5} & \mathbf{0 . 3 3} \text { to } 2.87 & \mathbf{0 . 5 5} & \mathbf{1 4} \\ \text { PLCC:Depth } & \mathbf{0 . 9 7} & \mathbf{0 . 4 5} & \mathbf{0 . 0 9} \text { to } \mathbf{1 . 8 5} & \mathbf{0 . 4 8} & \mathbf{1 5} \\ \text { PC:Ldim } & 0.69 & 0.70 & -0.68 \text { to } 2.05 & 0.21 & 9 \\ \text { PH:Ldim } & 0.20 & 0.33 & -0.47 \text { to } 0.84 & 0.11 & 5\end{array}$

11

$\mathrm{R}^{2}{ }_{\mathrm{GLMM}(\mathrm{m})}=0.81, \mathrm{R}^{2}{ }_{\mathrm{GLMM}(\mathrm{c})}=0.90$ 
1

Photo of a cleaner wrasse cleaning an anthias client fish

Fig. 1 The cleaner wrasse, Labroides dimidiatus, removes ectoparasites from the surface of a 'client' reef fish (Photo: L. dimidiatus cleaning an anthias, Pseudanthias squamipinnis, Red Sea, S. Gingins). 


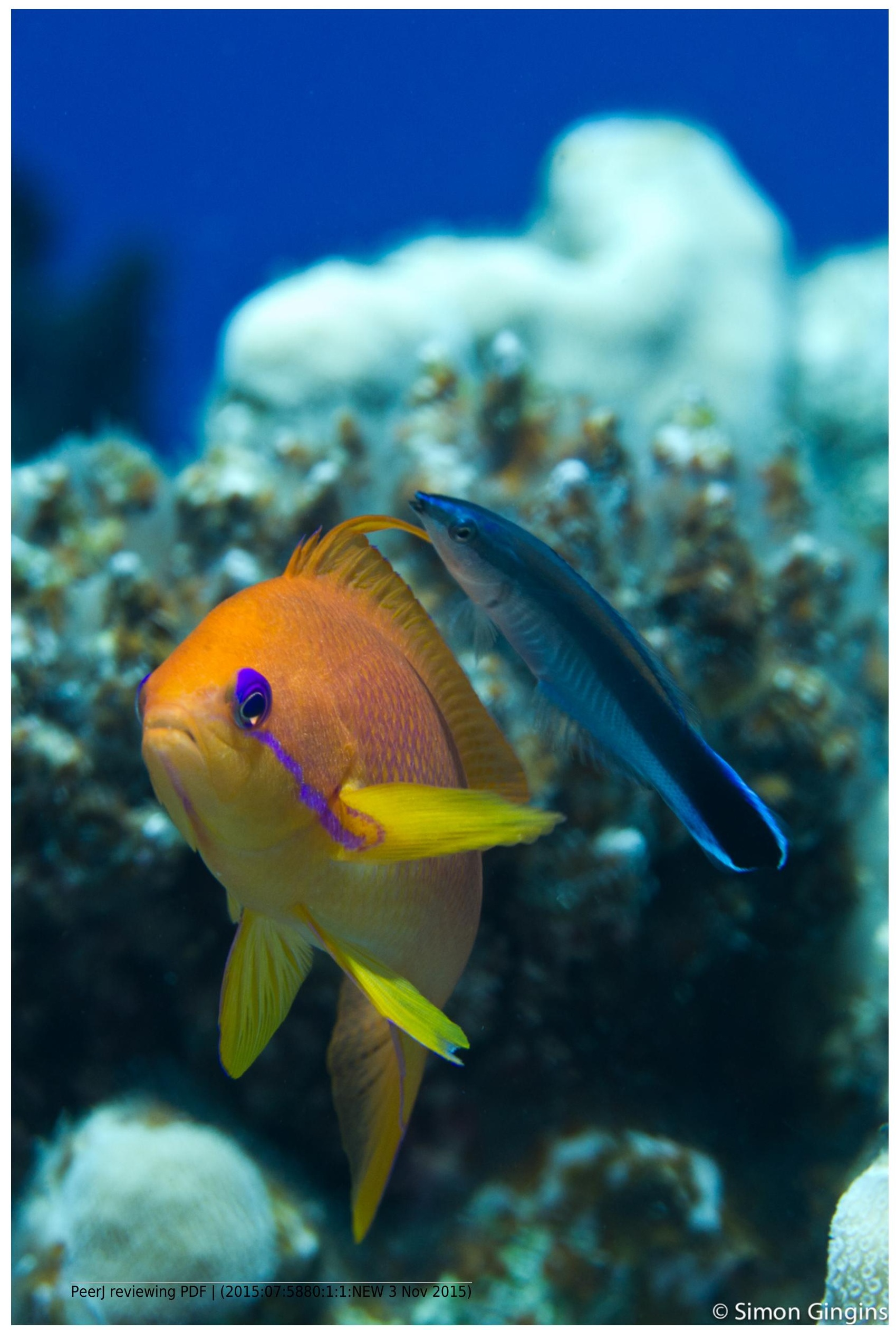


2

Study site map

Fig. 2 Map of the patch reefs and study area at Mersa Bareika, Ras Mohammed National Park, Egypt $\left(27^{\circ} 47^{\prime} 23.9^{\prime \prime} \mathrm{N}, 34^{\circ} 13^{\prime} 02.8^{\prime \prime} \mathrm{E}\right)$. The dotted line defines the park boundaries.

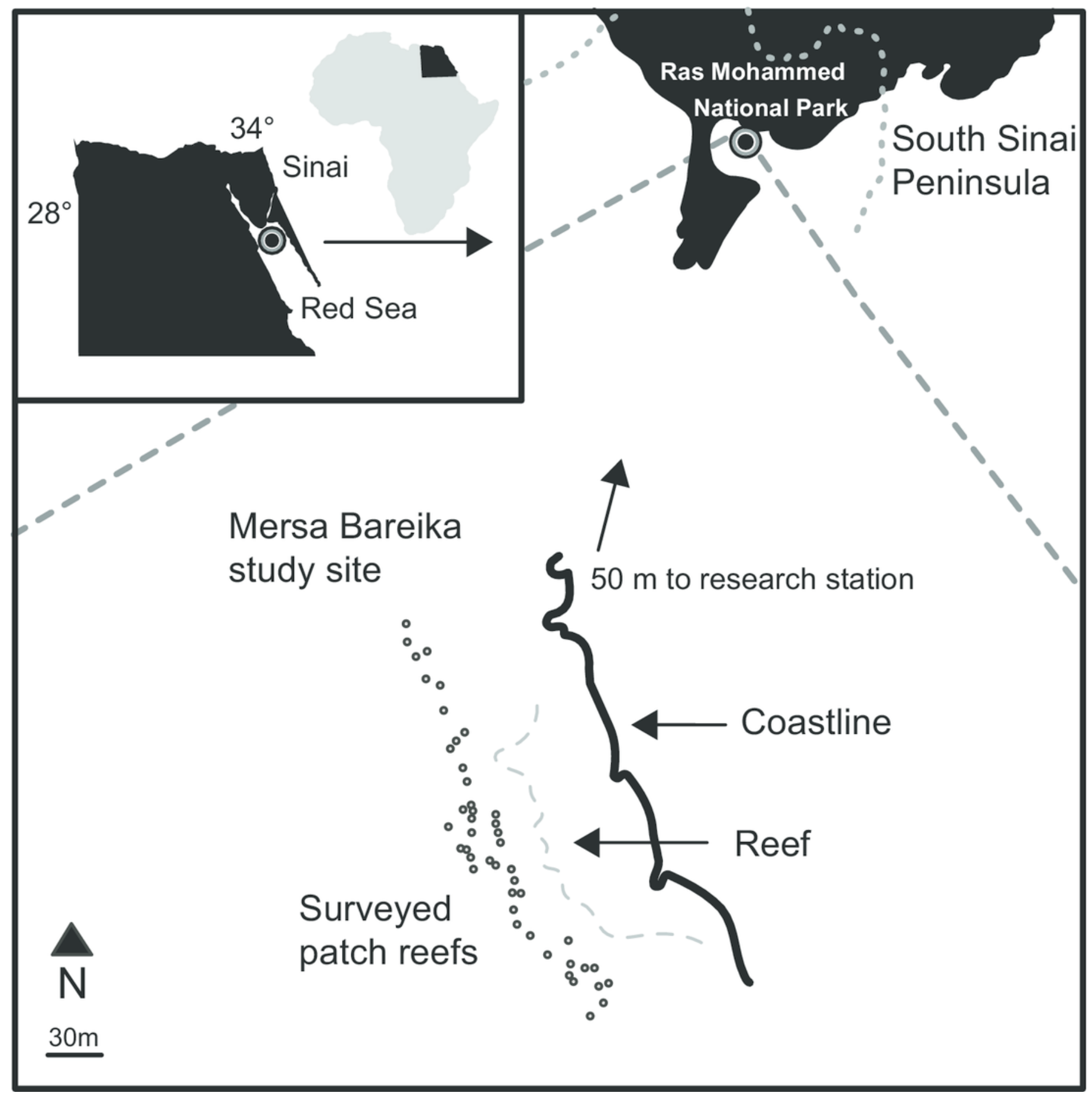

